\title{
Are nucleoli participating in programmed cell death? (MINI-REVIEW AND RECENT OBSERVATIONS)
}

\section{Karel Smetana}

Clinical Department, Institute of Hematology and Blood Transfusion, Prague, Czech Republic, Department of Pharmacology, Baylor College of Medicine, Houston, USA

\begin{abstract}
Summary
Despite numerous publications on nucleoli, their participation in terminal maturation and programmed cell death have not been studied extensively. On the other hand, some observations clearly indicate that terminal maturation and programmed cell death are accompanied by marked nucleolar changes which reflect the cessation of nucleolar biosynthetic activities. In addition, nucleolar changes in the course of terminal maturation may precede programmed cell death.
\end{abstract}

Keywords: nucleolus - erythrocytic and granulocytic precursors - terminal maturation - programmed cell death

\section{INTRODUCTION}

Despite numerous reports on nucleoli in the literature (see Busch and Smetana 1970, Wachtler and Stahl 1983, Pederson 1998), its role in terminal maturation, programmed cell death and apoptosis has been less well studied and understood (Martelli et al. 2001). The maturation compartments and terminal maturation stages of erythroid and granulocytic lineages are very convenient cells for such studies because they are well defined in both blood forming organs and peripheral blood (Bessis 1974).

\section{NUCLEOLAR CHANGES IN THE COURSE OF THE TERMINAL MATURATION AND PROGRAMMED CELL DEATH OF ERYTHROID AND GRANULOCYTIC PRECURSORS}

The terminal maturation stages of the granulocytic lineage are characterized by nuclear segmentation and heavy chromatin condensation (Bessis 1974). Micronucleoli in these cells are visible after visualization by demonstration methods for silver stained proteins characteristic of silver stained organizer regions (AgNORs) or electron microscopy. It should be mentioned that such nucleoli may lose RNA detectable by light microscopy (Likovský and Smetana 2000). These micronucleoli are characterized by significantly larger values of the nucleolar coefficient (the number of nucleoli per cell) when they are visualized by the silver reaction for AgNOR proteins than after staining for RNA (Fig. 1a,b). It should now be mentioned that the nucleolar coefficient of mature monocytes was also significantly larger in specimens immunostained for characteristic nucleolar proteins than in those stained for RNA (Smetana et al. 1997).

Terminal maturation stages of human or mammalian nucleated erythroid cells - erythroblasts - are characterized by the presence of a pyknotic nucleus which is finally expelled from the cell (Bessis 1974). In "normal" human terminal erythroblasts micronucleoli are still visible but only after staining for RNA and AgNORs or by conventional electron microscopy (Smetana 2002, Smetana et al. 2001). In addition, similarly as with mature granulocytes some micronucleoli of late erythroblasts might lose RNA because such nucleoli were present in a significantly larger number of these cells after visualization by silver reaction than after staining for RNA (Smetana 2001). 
Moreover, pathological erythroblasts of refractory anemia apparently lose nucleoli in light microscopy of specimens stained for RNA (Smetana et al. 1999). However, in some of these cells they may be still detected using the silver reaction for AgNORs (Smetana et al. 2001).

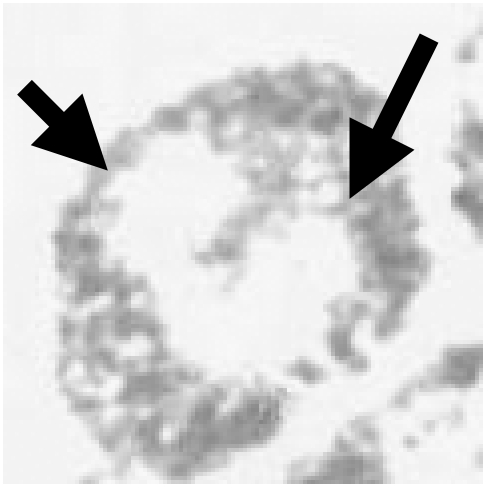

a
The structural organization of micronucleoli characteristic of the terminal maturation stages of granulocytic and erythroid precursors preceding the programmed cell death is variable but reflects three pathways of the cessation of nucleolar biosynthetic activities and the production of ribosomal precursors

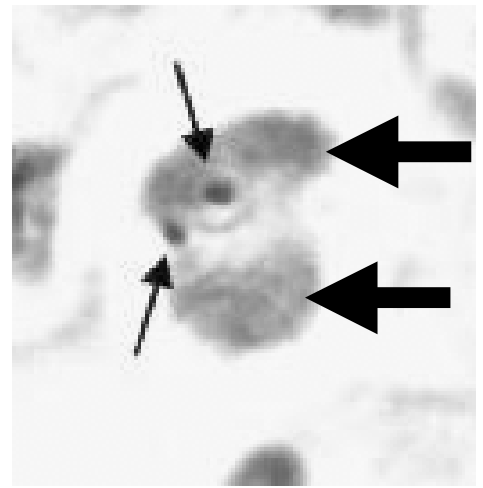

b

Fig. 1. Micronucleoli (arrows) are not seen in nuclei (large arrows) of mature granulocytes stained for RNA (a) but are clearly visible in specimens stained for AgNOR proteins with the silver reaction (b). The light microscopic images were magnified and processed using L-view and Power Point Microsoft programs (USA). Magnification approx. 3700x.

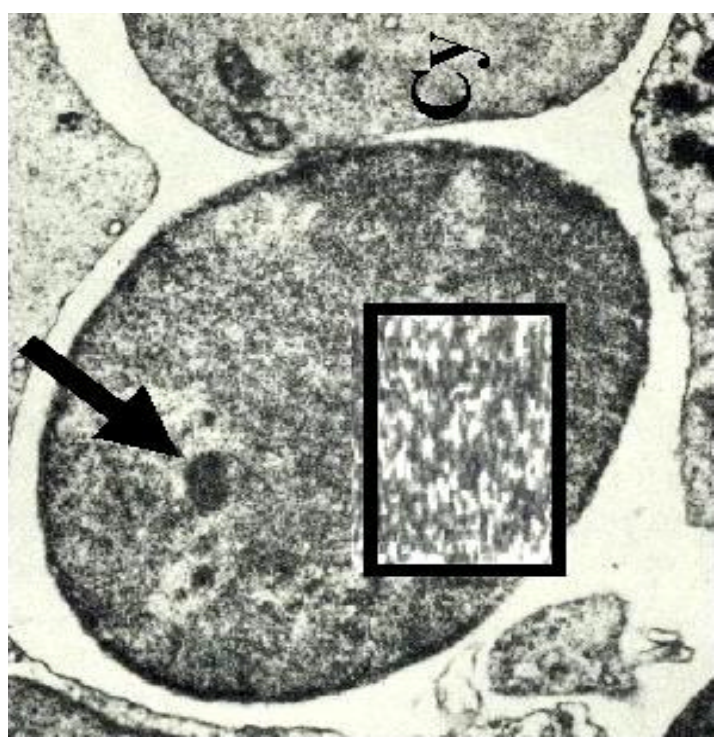

a

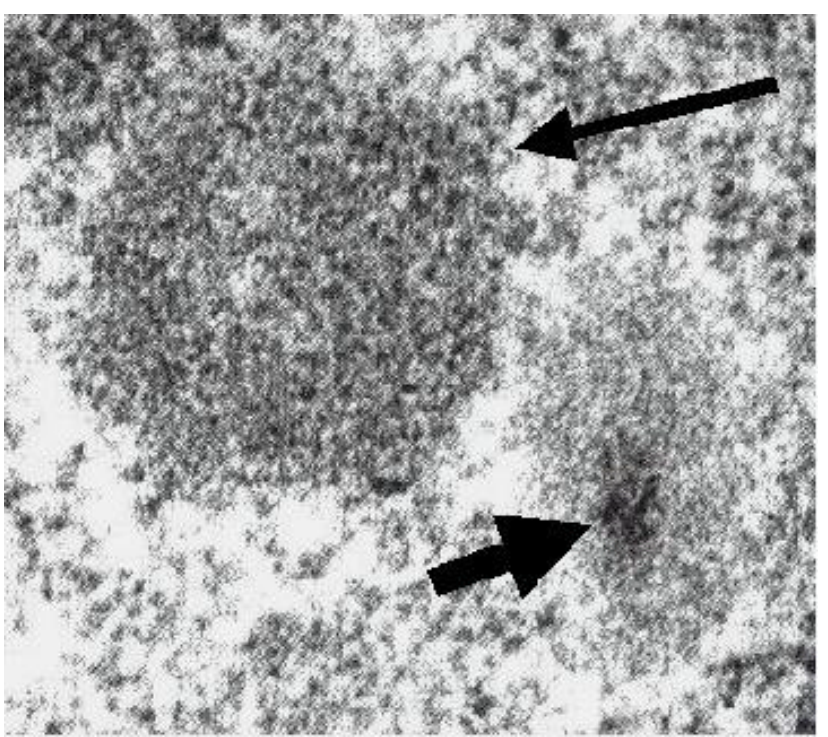

b

Fig. 2. Electron micrograph of a micronucleolus (arrow) in denucleating late erythroblast (a). The cytoplasm (Cy) will be the future reticulocyte. Note that the nucleolus mainly consists of dense fibrillar components (insert). Electron micrograph of an ultrathin section was taken using Philips 300 electron microscope (Philips, Holland), further magnified and processed as indicated in the Figure 1. Magnification approx. 19600x, insert 140000x.

Electron micrograph of a micronucleolus originating by nucleolar fragmentation (b). The micronucleolus consists mainly of dense granular components (large arrow). The other fragment of the nucleolus is composed of nucleolar protein of low electron density and few dense RNA containing components (thick arrow). For imaging procedure see the previous Figure. Magnification approx. 52000x. 


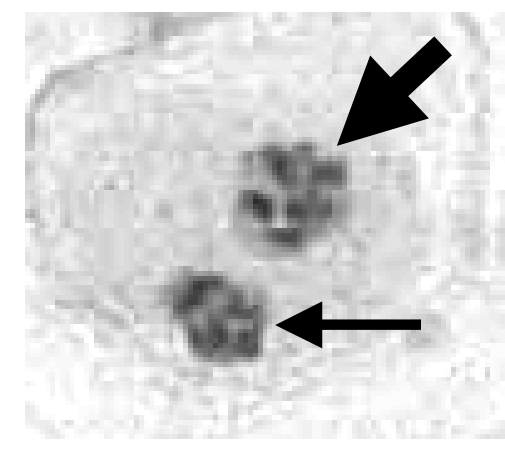

$\mathbf{a}$

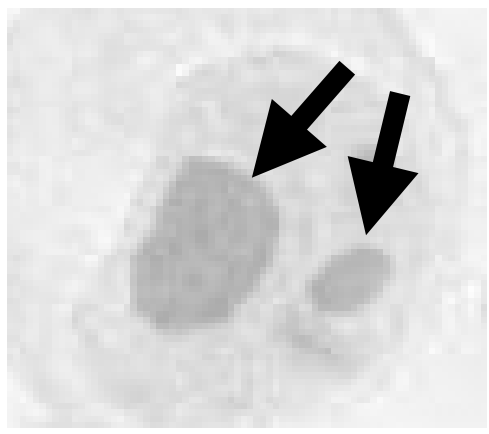

b

Fig. 3. A control leukemic precursor - HL-60 cell (a) contains nucleoli (arrows) with distinct silver stained particles representing AgNORs. Focused on the large nucleolus (thick arrow). In contrast, these particles are absent in large nucleoli (arrows) in a HL-60 apoptotic cell (b). The images were captured with Camedia digital photocamera C-4040 Zoom (Olympus, Japan), further magnified and processed using L-view and Power Point Microsoft programs (USA). Magnification approx. 5000x (a), 5500x (b).

(Smetana 1980, 2002). The segregation of nucleolar components is known to reflect the inactivation of the rRNA transcription.

The reduction of dense granular components might, apparently, reflect the cessation of the rRNA processing and assembly of preribosomal particles (Fig. 2a)(Pelliciari 2000). In contrast, the reduction of fibrillar components in nucleoli only reflects the cessation of the rRNA transcription (Fig. 2b). The retraction of chromatin from the nucleolar body might suggest the loss of the DNA (Smetana 1980). In addition, nucleoli in apoptotic erythroblasts may be part of ectopic nuclear RNP aggregates and may be expelled from the nucleus (Biggiogera and). It should be noted that the nucleoli in maturing mouse embryonic erythroblasts or nucleolated avian erythrocytes also lose RNA containing granular components and the resulting nucleolar remnants mainly consist of fibrillar centers and reduced fibrillar components (Zatsepina et al. 1998, Ochs and Smetana 1991). Thus, the terminal maturation preceding programmed cell death is ensured by the above mentioned mechanisms resulting in the cessation of the nucleolar RNA transcription or renewal of ribosomes which are necessary for the cell to synthesize proteins and live. In addition, there might be other consequences of the inactivation of other nucleolar functional activities (Pederson 1998) but they are less accessible to the structural analysis of individual cells at present.

When programmed cell death and apoptosis is produced without previous terminal maturation of granulocytic precursors by the 5 -aminolaevulinic acid induced photodynamic effect, characteristic changes of nucleolar structural components also indicate nucleolar participation but without the transformation of nucleoli to micronucleoli (Smetana et al. 2000). Apoptotic leukemic granulocytic precursors represented by HL-60 cells exhibit characteristic changes of the nuclear chromatin structure such as chromatin condensation, but without nuclear segmentation indicating terminal maturation (Smetana et al. 2000). In these apoptotic cells nucleoli are still large and possess RNA. On the other hand, such nucleoli exhibit a marked reduction or absence of AgNORs seen by light microscopy (Fig. 3a,b).

Electron microscopy of these cells also demonstrated a reduction of fibrillar centers in their nucleoli since their number decreased or they were absent in such nucleoli (Smetana et al., in preparation). From numerous previous studies it has been established that, using defined cytochemical procedures, AgNORs in the light microscope correspond to fibrillar centers and adjacent regions containing dense fibrillar components in the electron microscope (Schwarzacher and Wachtler 1983, Wachtler and Stahl 1993, Smetana et al. 1998, 1999). Since the transcription of the rRNA takes place in nucleolar regions adjacent to fibrillar centers (see Hozák, et al. 1994, Koberna et al. 2002, Melčák et al. 1996, Wachtler and Stahl 1993), it seems to be clear that in these apoptotic granulocytic precursors the nucleolar biosynthetic activity must be reduced. In addition, numerous light microscopic studies on AgNORs represented by silver stained particles clearly demonstrated that their number reflects the nucleolar biosynthetic as well as cell proliferation activity (see e.g. Derenzini 2000, Likovský and Smetana 1981, Smetana and Busch 1979). Needless to be added that apoptotic HL-60 cells do not proliferate (Smetana et al. 2000). At this occasion it should be mentioned that the reduction of AgNORs was also described in 
apoptotic epithelial cells after treatment with okadaic acid (Morimoto et al. 2001). In that case the reduction of AgNORs was produced by the cleavage of nucleolin which is one of main silver stained proteins of these nucleolar structures.

In the electron microscope compact nucleoli of apoptotic HL-60 cells without or with reduced fibrillar centers contained predominantly dense granular components and dense fibrillar components were less seen (Smetana et al., in preparation). Since the latter contain the newly transcribed rRNA (Wachtler and Stahl 1993), such ultrastructural organization of nucleoli in these apoptotic cells reflects the inhibited transcription of the rRNA.

\section{OTHER EVIDENCE}

All above discussed observations apparently suggest the nucleolar participation in the terminal maturation, programmed cell death and apoptotic process. In addition, there are also other studies which support such conclusions. The programmed cell death of mouse sperms and chicken erythrocytes in the presence of caspase inhibitors suggested that their death program may not depend on caspases. Moreover, chicken erythrocytes lose caspases as they mature (Weil et al. 1998). The translocation of a tumor supressor protein ING1 to the nucleolus apparently facilitates the apoptotic process (Scott et al. 2001) and the $37 \mathrm{kDa}$ protein DEDD (two death effector domains containing protein) is transferred into the nucleolus to shut of the biosynthetic activities (Stegh et al. 1998). In addition, the translocation of nucleophosmin and possibly other nucleolar proteins such as Ki67, topoisomerase I, Gu-RNA/DNA helicase from nucleoli may be also related to the induced apoptosis (see Busch 1999, Chan and Chan 1999). It should be mentioned that one of main nucleolar proteins - nucleophosmin apparently trigger apoptosis because its translocation occurs prior chromatin condensation and DNA fragmentation (Chan and Chan 1999).

\section{CONCLUSION}

In blood cells and possibly also in other cell types nucleoli apparently participate in the programmed cell death and apoptosis. It seem to be likely that these terminal cell events are preceded or accompanied by the decrease or cessation of nucleolar functional activities reflected by marked morphological and structural changes visible by both light as well as electron microscopy.

\section{ACKNOWLEDGEMENT}

This study was facilitated in part by the support of the Czech Ministry of Health and Busch Fund.

Received $11^{\text {th }}$ December 2002.

Published online $4^{\text {th }}$ March 2003.

\section{REFERENCES}

Bessis M.: Living Blood Cells and Their Ultrastructure. Springer, Berlin, 1973.

Biggiogera M. and C. Pelliciari: Heterogeneous ectopic RNP derived structures (HERDS) are markers of transcriptional arrest. FASEB J. 14: 828-834, 2000.

Busch H.:Nucleolar and nucleolonemal proteins of cancer cells. J. Tumor Marker Oncol. 12: 5-68, 1997.

Busch H. and K. Smetana: The nucleolus. Academic Press, New York, 1970.

Chan P.K. and F.Y. Chan: A study of correlation between NPM-translocation and apoptosis in cells induced by Daunomycin. Biochem. Pharmacol. 57: 1265-1273, 1999.

Derenzini M.: The AgNORs. Micron 31: 117-1120, 2000.

Hozák P., P.R. Cook, C. Schofer, W. Mosgoller, F. Wachtler: Site of transcription of ribosomal RNA and intranucleolar structure in HeLa cells. J. Cell Sci. 107: 639-678, 1994.

Koberna K., J. Malinský, A. Pliss, M. Masata, J. Večeřová, M. Fialová, J. Bednář, I. Raška: Ribosomal genes in focus: new transcripts label the dense fibrillar components and form clusters indicative of Christmas trees. J. Cell Biol. 157: 743-748, 2002.

Likovský Z. and K. Smetana: Further studies on the cytochemistry of the standardized silver staining of interfuse nucleoli in smear preparations of Yoshida ascetic sarcoma cells in rats. Histochemistry 72: 301-313, 1981.

Likovský Z. and K. Smetana: Nucleolar coefficient of granulocyte precursors and granulocytes after visualization of nucleoli by two different methods. Acta histochem. 102: 95-102, 2000

Martelli A.M., M. Zweyer, R.L.Ochs, P.L. Tazzari, G. Tabellini, P. Narducci, R. Bortul: Nuclear apoptotic changes: An overview. J. Cell. Biochem. 82: 634-646, 2001.

Melčák I., M.C. Risueno, I. Raška: Ultrastructural nonisotopic mapping of nuclear transcription sites in onion protoplasts. J. Struct. Biol. 116: 253-263, 1996. 
Morimoto Y., S. Kito, T. Ohba, H. Morimoto, H. Okamura, T. Haneji: Alteration of aryrophilic nucleolar organizer region associate (AgNOR) proteins in apoptosis - induced human salivary gland and human squamous carcinoma cells. J. Oral Pathol. Med. 30: 193-199, 2001.

Ochs R.L. and K. Smetana: Detection of fibrillarin in nucleolar remnants and the nucleolar matrix. Exp. Cell Res. 197: 183-190, 1991.

Pederson T.: The plurifunctional nucleolus. Nucleic Acids Res. 26: 3871-3876, 1998.

Scott M., F.M. Boisvert, F.M. Vieyera, R.N. Johnston, D.P. Bazett Jones, K. Riabowol: UV induces nucleolar translocation of ING1 through two distinct nucleolar targeting. Nucl. Acids Res. 29: 2052-2058, 2001.

Schwarzacher H.G. and F. Wachtler: Nucleolus organizer regions in nucleoli. Hum. Genet. 63: 89-99, 1983.

Smetana K.: Nucleoli in maturing blood cells. In S. Roath (ed.): Topical Reviews in Haematology I. Wright, Bristol 1980, 115-137.

Smetana K.: Structural features of nucleoli in blood, leukemic, lymphoma and myeloma cells. Eur. J. Histochem. 46: 125-132, 2002.

Smetana K. and H. Busch: Studies on silver stained nucleolar components. In H. Busch, S.T. Crooke, Y. Daskal (eds.), Effects of drugs on the cell nucleus. Academic Press, New York, 1979.

Smetana K., H. Cajthamlová, D. Grebeňová, Z. Hrkal: J. Photochem. Photobiol. B: The 5aminolaevulinic acid based photodynamic effects on nuclei and nucleoli of HL-60 leukemic granulocytic precursors. J. Photochem. Photobiol. B: Biol. 59: 80-99, 2000.

Smetana K., P.K. Chan, I. Jirásková, H. Busch: Nucleolar coefficient and cytochemistry of human blood monocytes. Life Sci. 60: 21992205, 1997.

Smetana K., I. Jirásková, J. Čermák: Incidence of nucleoli in erythroblasts of patients suffering from refractory anemia of myelodysplastic syndrome. Eur. J. Haematol. 63: 112-336, 1999.

Smetana K., I. Jirásková, K. Smetana Jr, J. Čermák: A short note on micronucleoli in the course of terminal maturation of human erythroblasts. Folia Biol. (Praha) 47: 14-17, 2001.

Smetana K., I. Jirásková., L. Perlaky, H. Busch: The silver reaction of nucleolar proteins in the main structural compartments of ring shaped nucleoli in smear preparations. Acta histochem. 101: 167-183, 1999.

Smetana K., I. Jirásková, M. Sedláčková, R. Dvořák, M. Špátová, P. Hozák: Preferential silver reaction of nucleolar regions adjacent to fibrillar centers in ring shaped nucleoli of leukemic lymphocytes. Acta histochem. 100: 257-270, 1998.

Stegh A.H., O. Schickling, A. Ehret, C. Scaffidi, C. Peterhansel, T.G. Hofmann, I. Grummt, P.H. Krammer, M.E. Peter: DEDD, a novel death effector domain-containing protein targeted to the nucleolus. EMBO J. 17: 5974-5986, 1998.

Wachtler F. and E. Stahl: The nucleolus: A structural and functional interpretation. Micron 24: 473-505, 1993.

Weil M., M.D. Jacobson, M.C. Raff: Are caspases involved in the death of cells with a transcriptionally inactive nucleus? J. Cell Sci. 111: 2707-2715, 1998.

Zatsepina O.V., Chelidze, Y.S. Chentsov: Changes in the volume and fibrillar centers with the inactivation of nucleoli at erythropoiesis. J. Cell Sci. 9: 439-448, 1988.

\section{Address:}

Karel Smetana, Institute of Hematology and Blood Transfusion, U nemocnice 1, 12820 Praha 2, Czech Republic; e-mail: karel.smetana@uhkt.cz 